\title{
Enhancement and Investigation of Biodegradability of Poly(Methyl Methacrylate) and Poly(vinyl chloride) by Blending with Cellulose Derivatives
}

\section{Yethadka Narahari Sudhakar}

Christ University

Muthu Selvakumar ( $\nabla$ chemselva78@gmail.com )

Manipal Institute of Technology https://orcid.org/0000-0003-3769-2752

D KRISHNA BHAT

NITK: National Institute of Technology Karnataka

\section{Research Article}

Keywords: Polymers, Blending, Biodegradation, Degradation tests, Miscibility, microbe

Posted Date: February 11th, 2021

DOI: https://doi.org/10.21203/rs.3.rs-184118/v1

License: (c) (i) This work is licensed under a Creative Commons Attribution 4.0 International License.

Read Full License 


\section{Abstract}

Presently, society needs a more eco-friendly alternative for non-biodegradable polymers, nonetheless, the synthetic polymers have established the market because of cost and easy to manufacture. To address the challenge of reducing the lifetime of degradation of these polymers the scope of blending natural biopolymers is effective. This paper focuses on confirming the effectiveness of biodegradation in the molecular level of polymer blends between synthetic polymers and biopolymers. The synthetic polymers such as poly(methyl methacrylate) (PMMA) and poly(vinyl chloride) (PVC) were blended with varying compositions of biodegradable cellulose acetate butyrate (CAB). Using dimethylformamide (DMF) the films of PMMA/CAB, PVC/CAB blends were prepared by the solution casting method. Four different methods for studying biodegradability of these blends namely, soil burial test, enzymatic degradation, activated sludge degradation followed by microbial degradation was performed. The confirmation of degradation was done by NMR, FTIR and Gel Permeation Chromatography (GPC) studies. Moreover, degradation analyses were determined by weight loss method. Sufficient biodegradability was shown with an increase in $\mathrm{CAB}$ content in the blend. This work provides an approach for bringing about the degradation of synthetic polymers without much compromise on their properties. Also the type of microorganisms that effectively degrades these polymer bends can be known.

\section{Introduction}

Common polymers like polypropylene, PMMA, PVC, polyethylene are extensively used and reusing or recycling them is a serious task. Even their composites add-on to the non-biodegradable wastes throughout the world. The alternative is the use of biodegradable polymers which mainly originates from renewable sources. However, their properties of brittleness, low thermal stability, water vapor permeability and uncontrolled molecular weight are main challenges that are yet to overcome when compared to synthetic polymers. Moreover, there are no single biodegradable polymers which can be used as such in applications such as carry bags, biomedical, food package, etc., Therefore, it is desirable to modify existing synthetic polymers by blending with a wide range of biopolymers, fillers and bring about enhanced degradation [1]. Some researchers have attempted for preparing these kinds of composite polymers by including biopolymers into synthetic polymers [2-4]. Optimum balancing of physical and biodegradation properties of biopolymer/synthetic polymer blends will minimize the waste disposal problems. Biopolymer nanocomposites have a scope in industrial sectors as it is easy to process and have slightly greater biodegradation property [1]. Cellulose is a biopolymer that is found in abundance in wood and bacterial origin. As untreated cellulose behaves as thermosetting polymer and has less solubility. On the other hand cellulose derivatives are thermoplastics in nature and easy to process which makes it blend with synthetic polymers. Cellulose derivatives are readily biodegradable by microorganisms that utilize cellulose enzymes, but due to the additional acetyl groups cellulose requires the presence of esterases. Thereby the blending of the CAB will induce biodegradation in the synthetic polymer. PMMA a versatile synthetic polymer has enormous useful properties required in industrial and pharmaceutical applications. The literature survey on PMMA/Cellulose shows that the higher 
concentration of cellulose improves the bonding within them. PMMA/Cellulose blends [5] were subjected to dynamic mechanical analysis showed greater interaction at a high concentration of cellulose with PMMA. The nanocomposites with PMMA molecules covalently grafted to cellulose exhibited much higher optical transparency, thermal stability, and hygro-mechanical properties than the control samples [6]. PMMA/2,2,6,6-tetramethylpiperidyl-1-oxyl oxidized CNFs (PMMA/TOCN) nanocomposites with high transparency, controllable birefringence and enhanced mechanical properties exhibit great potential for the applications in the optical devices and engineering field [7]. Porosity and stability can be seen in membranes based on CA/PMMA which was used for separation of proteins and toxic heavy metals [8]. To effectively modify the synthetic polymer, few grafted copolymers based on cellulose-g-PMMA found to be more moisture resistant and also exhibited better chemical and thermal resistance [9]. Carboxymethyl cellulose-g-PMMA showed thermal stability better than that of PMMA [10]. Nevertheless, none of the literature discussed the biodegradation of these fibers/films. Hence, this paper focuses on the aspects of PMMA/CAB degradation. One more synthetic polymer PVC which is dominated in pipe and automobile industries is of major concern as this polymer is non-degradable. The preparation of PVC and biopolymer composites is challenging and requires more study. Cellulose Acetate (CA) and PVC nanofiber mats were electrospun into nanofibers which showed smooth fibers at 14\% CA and solution concentration had a significant influence on the tensile strength of the nanofiber mats [11]. It was found that there are no biodegradable studies on PVC/cellulose derivative films. CAB as one of the biodegradable and biocompatible cellulose materials has attracted much attention in both academic and industrial fields ranging from a food package, biomedical products, clothing to automotive materials [12]. Hence, this paper reports for the first time the preparation and degradation of PVC/CAB film in various standard conditions. Different ratios of films PMMA/CAB, PVC/CAB blends were prepared and characterized chemical, spectroscopic, and chromatographic techniques. A comparison of the mode of degradation was made to understand the microbial degradation as well as the physical degradation of the polymer. This paper has been split into two parts, (i) The first part deals using soil-burial, activated sludge, buffer weight loss of polymer blend film monitored, and also using soil-burial method mechanical strength of films are monitored for two months $[13,14]$. (ii) The second part deals with the degradation of polymer to smaller elements was monitored by microbial degradation method and verified using FTIR, NMR, GPC techniques $[15,16]$.

\section{Materials And Methods}

PMMA, PVC, and CAB were obtained from commercial sources. The viscosity average molecular weight of PMMA, PVC, and CAB were 75000, $101000,70000 \mathrm{~g} \mathrm{~mol}^{-1}$, respectively. Bushnell-Hass broth and Bushnell-Hass agar (BH, Hi-Media) were used as the medium. All other chemicals used were of analytical reagent grade.

\section{Preparation of PMMA/CAB and PVC/ CAB films}


Dimethylformamide (DMF) was used as a common solvent for preparing polymer solutions of $\mathrm{CAB}$ and PMMA and the preparation of PVC-CAB polyblends. We have previously prepared synthetic/natural polymer blend and studied their biodegradability the procedure is the same as Krishna et al. [14]. Briefly, $1 \mathrm{~g}$ of polymers was dissolved in $50 \mathrm{~mL}$ of DMF and at ambient temperature. Composites were prepared by mixing different ratios of blends. The solutions were stirred well for an hour and solution cast on the petri dish. Films of 0.2-0.4 mm were obtained.

\section{Soil Burial Degradation study $[17,18]$}

As reported in the literature about the soil nature [14] the blend films were subjected to soil burial tests by maintaining $25 \%$ moisture weight. The films were taken out, washed with water, dried and weighed again accurately to know the degradation in the intervals of 5, 10 and 15 days. In the case of soil adhering to the blend films, the films were washed and extracted with DMF. Using filtration, the soil was separated after evaporating the solvent residue. The experiment was repeated thrice and results were reproducible with $\pm 2 \%$ error.

\section{Activated Sludge Degradation study}

Activated sludge was kindly provided by BASF Company. The characteristics of the sludge have been reported in [14]. Aeration was provided for jars containing fixed volumes of activated sludge and blend films. The degraded films were tested after 5, 10, 15 days after washing with distilled water and drying at $60^{\circ} \mathrm{C}$. The experiment was repeated thrice and results were within $\pm 3 \%$ error.

\section{Enzymatic Degradation study}

The films were tested as reported in [14] using enzyme lipase from the porcine pancreas in buffer solution. The test was reproduced thrice with $\pm 3 \%$ error.

\section{Sample preparation and bacteria used}

Bushnell-Hass agar (BH, Hi-Media) and Bushnell-Hass broth were used for detecting the biodegradation process. The $\mathrm{pH}$ of the medium was set to 7 . The mixture of bacteria culture by pseudomonas, E-coli, Bacillus, and Klebsiella was used in this study. Commercially available enzyme Lipase was obtained from Hi-Media. As the sole carbon source about $10 \mathrm{~mL}$ of CAB, PMMA/CAB (30:70), PMMA/CAB (50:50), $\mathrm{PVC} / \mathrm{CAB}$ (30:70), PVC/CAB (30:70) solutions with control was taken in Erlenmeyer flasks and dissolved in dichloromethane. $50 \mathrm{ppm}$ of mixed culture (pseudomonas, E-coli, Bacillus, Klebsiella) was inoculated. The test was carried as reported in [14]. After 30 days of the incubation period, the residual blend films were extracted with an equal volume of dichloromethane (DCM). The resultant solute of polymer blends $(1 \mu \mathrm{L})$ after evaporating the solvent was analyzed by using FTIR, NMR and Gel Permeation Chromatography (GPC). Tetrahydrofuran (THF) was used as eluent with a flow rate of $1 \mathrm{ml} \mathrm{min}^{-1}$ at $60^{\circ} \mathrm{C}$.

\section{Result And Discussions}


CAB was found to be miscible in both PVC and PMMA solutions [14] indicating CAB chains have specific interaction with PVC and PMMA.

\section{Soil burial degradation}

Soil degradation test of PMMA/CAB blend films showed 0.3 to $2.95 \%$ of degradation order, while the $\mathrm{PVC} / \mathrm{CAB}$ blend films reduced to $2.4 \%$. The blend with more CAB showed high degradation as seen in Fig. $1 \mathrm{a}$ and $1 \mathrm{~b}$. The polymers exposed to soil might have initially experienced biodegradation, where microorganisms consume the natural cellulose component. Consequently, the oxygen can attack the newly generated surface with the formation of peroxides, hydroperoxides, oxides etc., which promote the scission of polymeric chains into small fragments. These chains are more susceptible to microorganism attack $[17,18]$. Soil bacteria and fungi might be responsible for degradation [19].

\section{Enzymatic degradation}

In the presence of phosphate buffer the blends are initially hydrolyzed and then followed by enzymatic degradation. Lipase from porcine pancreas under controlled environment was able to degrade about 0.9$4.95 \%$ for PMMA/CAB blend and $0.6-4.42 \%$ for PVC/CAB blends (Fig. $1 \mathrm{c}$ and $1 \mathrm{~d}$ ). Within fifteen days the blends showed biodegradation to an extent pure $\mathrm{CAB}$. Therefore, enzymes have a major contribution to the biodegradation of the blends.

\section{Degradation in activated sludge}

The blends subjected to activated sludge for 15 days showed degradation of about 1.1 to $5.21 \%$ for PMMA/CAB blends and 0.9 to $4.87 \%$ for PVC/CAB blends. The polymer blend with higher CAB content showed maximum degradation (Fig. $2 a$ and $2 b$ ). The results comparatively showed higher degradation than any other methods used maybe because of the combined effect of microbial degradation and hydrolysis [20, 21].

\section{Tensile properties}

Figure $2 \mathrm{c}$ and $2 \mathrm{~d}$ show the tensile properties of PMMA-CAB, PVC-CAB blend films for different days. In this study also the tensile strength of the blend films decreases with increasing days. This result strongly proves the degradation of the synthetic polymers in the presence of CAB.

\section{Enumeration of bacteria during degradation}

The control and test samples containing polymer blends were examined at intervals of five days for 30 days (Fig. 3). The bacteria recovery in control showed exponential growth than test samples. The bacterial count was about $5.1 \times 10^{5} \mathrm{CFU} / \mathrm{mL}$ for control on the fifth day while test samples remained below $2.1 \times 10^{5} \mathrm{CFU} / \mathrm{mL}$. A gradual increase in bacterial count in test samples was noticed with an increase in days. Killing efficiency between the test sample and control showed no significant difference. This point out that present blend polymer is comparatively stable up to fifteen days, thereafter due to regeneration capability of bacteria the bacterial count increases in remaining days. Even significant 
changes in the $\mathrm{pH}$ of the test solutions were observed. The initial $\mathrm{pH}$ value of $7.0 \pm 0.2$ was reduced to 6.8 in 30:70 (PMMA/CAB) systems. Similar results were obtained for PVC/CAB blends.

\section{Enumeration of the enzyme during degradation}

The $\mathrm{BH}$ medium was taken in five sets of Erlenmeyer flasks and commercially available enzyme lipase was used for the efficiency studies. $250 \mathrm{~mL}$ of BH medium +250 units per $10 \mathrm{~mL}$ of lipase was dissolved in phosphate buffer. The bacterial count was done at a regular interval of five days. As the enumeration of bacteria data during degradation the enumeration of the enzyme showed a similar increase in the bacterial count with an increase in days. The overall mechanism of enzyme and bacteria degradation of polymer blends is shown in scheme 1 .

\section{FTIR analysis of blend polymer degradation}

FTIR spectra of pure CAB at different stages of degradation are shown in Fig. 4a. Before biodegradation the spectrum (a) shows the cellulose characteristic bands at $3484 \mathrm{~cm}^{-1}, 2984 \mathrm{~cm}^{-1}$ (C-H aliphatic stretch); $1743 \mathrm{~cm}^{-1}$ ( $\mathrm{C}=0$ carbonyl group), $1092 \mathrm{~cm}^{-1}$ ( $\mathrm{C}=0$ stretch for C-O-C alicyclic anhydride group); $911 \mathrm{~cm}^{-1}$ (C-H stretch for substituted benzene). Spectrum (b) for bacteria degradation, the characteristic bands at $3607 \mathrm{~cm}^{-1}$ (OH stretch); 2924 (C-H aliphatic stretch); 2111 (C-H aliphatic stretch); 1282 (C-0 stretch for alicylic anhydride group), 787 (mono substituted benzene) diminished. Spectrum (c) for enzyme degradation, all the characteristic stretching frequency showed less intensity indicating polymer has reduced to simpler elements [22, 23]. FTIR spectra of PMMA/CAB (30:70) at different stages of degradation are shown in Fig. 4b. Before biodegradation the spectrum (a) shows the characteristic bands at $3446 \mathrm{~cm}^{-1}(\mathrm{OH}), 2936$ (C-H aliphatic stretch), $1743 \mathrm{~cm}^{-1}$ (C = O carbonyl group), $1365 \mathrm{~cm}^{-1}$ (C-H def for methyl group), $576 \mathrm{~cm}^{-1}$, (C-H stretch for monosubstituted benzene). Spectrum (b) shows signs of degradation having the characteristic bands at $3421 \mathrm{~cm}^{-1}(\mathrm{OH}), 2931$ (C-H aliphatic stretch), $1743 \mathrm{~cm}^{-1}$ $(\mathrm{C}=\mathrm{O}$ carbonyl group) reduced. The same diminishing of characterization stretching frequency in the spectrum (c) for enzyme degradation is observed]. FTIR spectra of PMMA/CAB (50:50) at different stages of degradation are shown in Fig. 4c. Spectrum (a) shows the characteristic bands at $3471 \mathrm{~cm}^{-1}(\mathrm{OH})$, 2832 (C-H aliphatic stretch); $2017 \mathrm{~cm}^{-1}$ ( $\mathrm{C}=\mathrm{O}$ carbonyl group) $1741 \mathrm{~cm}^{-1}$ (C = O carbonyl group), 1446 $\mathrm{cm}^{-1}$ ( $\mathrm{C}=\mathrm{C}$ stretch in aromatic nuclei) $887 \mathrm{~cm}^{-1}$ (C-H stretch for substituted benzene). In spectrum (b) characteristic stretching frequency is diminished in 400 to $600 \mathrm{~cm}^{-1}$. In enzymatic degradation spectrum (c), stretching frequency is observed but the intensity of peak is less. This implies that the degradation has occurred in the blend film. FTIR spectra of PVC/CAB (30:70) at different stages of degradation are shown in Fig. 4d. Spectrum (a) shows the characteristic bands at $3495 \mathrm{~cm}^{-1}(\mathrm{OH}), 2974$ (C-H aliphatic stretch); $2104 \mathrm{~cm}^{-1}$ ( $\mathrm{C}=0$ carbonyl group), $1756 \mathrm{~cm}^{-1}$ ( $\mathrm{C}=0$ carbonyl group), $1408 \mathrm{~cm}^{-1}$ ( $\mathrm{C}=\mathrm{C}$ stretch in aromatic nuclei) $887 \mathrm{~cm}^{-1}$ (C-H stretch for substituted benzene). Spectrum (b) shows the bacteria degradation wherein all the stretching frequency is in less intensity, whereas in enzyme degradation all the frequency is diminished [24]. 


\section{${ }^{1} \mathrm{H}$ NMR analysis of blend polymer degradation}

Table 1 shows the functional groups of the before and after biodegradable polymers, respectively. The ${ }^{1} \mathrm{HNMR}$ spectra of before and after degradation samples are shown in Fig. 5a for pure CAB, Fig. 5b for 30:70 PMMA/CAB, Fig. 5c for 50:50 PMMA/CAB, Fig. 5d for 30:70 PVC/CAB. PMMA is a proton acceptor polymer and $\mathrm{CAB}$ is a proton donor polymer and they are found to be miscible due to hydrogen bonding. Before degradation, as per the CAB structure point of view, four ester groups are present in the 6, 3, 2 and 7 positions. One more ester group is formed due to blending with PMMA. These ester groups show multiplet peaks between 0.10 to $2.5 \mathrm{ppm}$. The $\mathrm{CH}_{2}$ aliphatic protons can be observed between 2.19 and $2.29 \mathrm{ppm}$. Another acetylenic proton peak is observed between 2.19 and $2.29 \mathrm{ppm}$. The aliphatic methylene $\left(\mathrm{CH}_{2}\right)$ peaks are noticed at 1.1 and $1.6 \mathrm{ppm}$ and the methyl protons peaks are observed at 0.86 ppm. The peak at $3.5 \mathrm{ppm}$ is due to vinyl compounds $[13,16,23,24]$. After 15 days of biodegradation plenty of small peaks are observed in the region of 1.5 to 5 , because of the breakage of long-chain polymers and hydrolytic degradation of esters into $\mathrm{CO}_{2}$ and $\mathrm{H}_{2} \mathrm{O}$. 
Table 1

NMR Chemical shift values of before and after degradation of polymer blends

\begin{tabular}{|c|c|c|c|c|}
\hline \multirow[t]{2}{*}{ Compound } & \multirow[t]{2}{*}{ Position } & $\delta$ (ppm) & $\delta$ (ppm) & \multirow[t]{2}{*}{ Remarks } \\
\hline & & $\begin{array}{l}\text { Before } \\
\text { degradation }\end{array}$ & $\begin{array}{l}\text { After } \\
\text { degradation }\end{array}$ & \\
\hline \multirow[t]{5}{*}{ A: Pure $C A B$} & 7 & 3.7 & 2.3 & \multirow{5}{*}{$\begin{array}{l}\text { Due to the splitting of carbonyl } \\
\text { compounds, } \mathrm{CH}_{3}, \mathrm{CH}_{2}, \mathrm{C}=\mathrm{C} \text { the } 3-5 \text { small } \\
\text { peaks are observed. }\end{array}$} \\
\hline & 6 & 2.0 & 2.2 & \\
\hline & 2 & 1.9 & 1.2 & \\
\hline & 3 & 1.9 & 1.7 & \\
\hline & $-\mathrm{CH}_{3}$ & $0.9-1.2$ & $0.9-1.2$ & \\
\hline \multirow{5}{*}{$\begin{array}{l}\text { B: } \\
\text { PMMA/CAB } \\
(30: 70)\end{array}$} & 7 & 3.7 & 2.3 & \multirow{5}{*}{$\begin{array}{l}\text { Due to the splitting of carbonyl } \\
\text { compounds, } \mathrm{CH}_{3}, \mathrm{CH}_{2}, \mathrm{C}=\mathrm{C} \text { the } 3-5 \text { small } \\
\text { peaks are observed. }\end{array}$} \\
\hline & 6 & 2.0 & 2.2 & \\
\hline & 2 & 1.9 & 1.2 & \\
\hline & 3 & 1.9 & 1.7 & \\
\hline & $-\mathrm{CH}_{3}$ & $0.9-1.2$ & $0.9-1.2$ & \\
\hline \multirow{5}{*}{$\begin{array}{l}\text { C: } \\
\text { PMMA/CAB } \\
(50: 50)\end{array}$} & 7 & 3.7 & 2.3 & \multirow{5}{*}{$\begin{array}{l}\text { Due to the splitting of carbonyl } \\
\text { compounds, } \mathrm{CH}_{3}, \mathrm{CH}_{2}, \mathrm{C}=\mathrm{C} \text { the } 3-5 \text { small } \\
\text { peaks are observed. }\end{array}$} \\
\hline & 6 & 2.0 & 2.2 & \\
\hline & 2 & 1.0 & 1.2 & \\
\hline & 3 & 1.4 & 1.7 & \\
\hline & $-\mathrm{CH}_{3}$ & $0.9-1.2$ & $0.9-1.2$ & \\
\hline \multirow{5}{*}{$\begin{array}{l}\text { D } \\
\text { PVC/CAB } \\
(30: 70)\end{array}$} & 7 & 3.7 & 2.3 & \multirow{5}{*}{$\begin{array}{l}\text { Due to the splitting of carbonyl } \\
\text { compounds, } \mathrm{CH}_{3}, \mathrm{CH}_{2}, \mathrm{C}=\mathrm{C} \text { the } 3-5 \text { small } \\
\text { peaks are observed. }\end{array}$} \\
\hline & 6 & 2.0 & 2.2 & \\
\hline & 2 & 1.0 & 1.2 & \\
\hline & 3 & 1.4 & 1.7 & \\
\hline & $-\mathrm{CH}_{3}$ & $0.9-1.2$ & $0.9-1.2$ & \\
\hline
\end{tabular}




\begin{tabular}{|lllll|}
\hline Compound & Position & $\begin{array}{l}\delta(\mathrm{ppm}) \\
\text { Before } \\
\text { degradation }\end{array}$ & $\begin{array}{l}\boldsymbol{\delta}(\mathrm{ppm}) \\
\text { After } \\
\text { degradation }\end{array}$ & Remarks \\
\hline $\mathrm{E}$ & 7 & 3.7 & 5.0 & $\begin{array}{l}\text { Due to the splitting of carbonyl } \\
\text { compounds, } \mathrm{CH}_{3}, \mathrm{CH}_{2}, \mathrm{C}=\mathrm{C} \text { the } 3-5 \text { small } \\
\text { peaks are observed. }\end{array}$ \\
$\begin{array}{l}\mathrm{PVC} / \mathrm{CAB} \\
(50: 50)\end{array}$ & 6 & 2.0 & 3.7 & \\
& 2 & 1.0 & 2.0 & \\
& 3 & 1.4 & 1.0 & \\
& $-\mathrm{CH}_{3}$ & $0.9-1.2$ & 1.4 & \\
& & & $0.9-1.2$ & \\
\hline
\end{tabular}

\section{GPC characterization}

GPC calibrated was PEO/PEG standards [12] and molecular weights calculated before and after bacterial degradation are shown in Table 2. The blend film containing high $C A B$ showed greater degradation as observed in molecular weight. Figure $6 a$ to $6 \mathrm{~d}$ shows GPC response of PMMA/CAB (30:70), PVC/CAB (30:70), PMMA/CAB (50:50), PVC/CAB (50:50), respectively. The decrease in molecular weight shown in spectral data matched with NMR and FTIR studies. Thus, it implies that biodegradability increases when synthetic polymers are modified using natural polymer like CAB. 
Table 2

GPC characterization and molecular weight values of before and after degradation of polymer blends

\begin{tabular}{|c|c|c|c|}
\hline Sample & $\begin{array}{l}\text { Molecular weight before } \\
\text { degradation }\end{array}$ & $\begin{array}{l}\text { Molecular weight after } \\
\text { degradation }\end{array}$ & Difference \\
\hline $\mathrm{A}(\mathrm{CAB})$ & 92186 & 77993 & 14193 \\
\hline Peak 1 & 6421 & 5238 & 1065 \\
\hline \multicolumn{4}{|l|}{ Peak 2} \\
\hline B & 92462 & 84791 & 7491 \\
\hline $\begin{array}{l}\text { PMMA/CAB } \\
(50: 50)\end{array}$ & 6473 & 5900 & 573 \\
\hline \multicolumn{4}{|l|}{ Peak 1} \\
\hline \multicolumn{4}{|l|}{ Peak 2} \\
\hline \multirow{2}{*}{$\begin{array}{l}\text { C PMMA/CAB } \\
(30: 70)\end{array}$} & 92186 & 80910 & 11276 \\
\hline & 6421 & 5477 & 944 \\
\hline \multicolumn{4}{|l|}{ Peak 2} \\
\hline D & 85878 & 79176 & 6702 \\
\hline PVC/CAB (50:50) & 6475 & 5574 & 905 \\
\hline \multicolumn{4}{|l|}{ Peak 1} \\
\hline \multicolumn{4}{|l|}{ Peak 2} \\
\hline$E$ & 99440 & 78348 & 21092 \\
\hline PVC/CAB (30:70) & 6271 & 5639 & 632 \\
\hline \multicolumn{4}{|l|}{ Peak 1} \\
\hline Peak 2 & & & \\
\hline
\end{tabular}

\section{Conclusion}

The problem of least understood biodegradation of synthetic polymer when blended with natural polymer is solved in this paper. The weight loss, bacterial, enzymatic methods were used to study biodegradation of blend polymers. The results obtained from FTIR, NMR and GPC indicated positive response for biodegradation of blend films in which the content of $C A B$ in more. Moreover, pure CAB partially degraded probably because of the reduced number of free hydroxyls enhanced the interaction with water and inhibited enzymatic hydrolysis. Whilst, in less water containing solid culture medium, synthetic polymer blended CAB showed biodegradation. 


\section{Declarations}

\section{Conflict of interest}

The author declare that they have no competing interest.

\section{References}

1. Sarang S.; Bari,; Aniruddha C.; Satyendra M. Biodegradable polymer nanocomposites: An overview. Polym. Reviews, 2016, 56:2, 287-328,

2. Kweon, D.K.; Cha, D.S.; Park, H.J.; Lim, S.T. Starch-g-polycaprolactone copolymerization using diisocyanate intermediates and thermal characteristics of the copolymers. J. Appl. Polym. Sci., 2000, 78,986

3. Albertsson, C.A.; Ljungquist, O. Degradable polyesters as biomaterials. Acta Polymerica, 1998, 39, 95

4. Tudorachi, N.; Cascaval, N.C.; Rusu, M. Biodegradable polymer blends based on polyethylene and natural polymers. Degradation in soil, J. Polym. Eng., 2000, 20, 287

5. Merenga A. S.; Katana G. A. Dynamic Mechanical Analysis of PMMA-Cellulose Blends, Int. J. Polym. Mater., 2010, 60:2, 115-123

6. Boujemaoui A.; Ansari F.; Berglund L. A. Nanostructural Effects in High Cellulose Content Thermoplastic Nanocomposites with a Covalently Grafted Cellulose-Poly(methyl methacrylate) Interface. Biomacromolecules, 2019, 20, 598-607.

7. Huang, T.; Kuboyama, K.; Fukuzumi, H.; Toshiaki O. PMMA/TEMPO-oxidized cellulose nanofiber nanocomposite with improved mechanical properties, high transparency and tunable birefringence. Cellulose, 2018, 25, 2393-2403

8. Vidya, S.; Mohan, D. Application Studies of Cellulose Acetate and Polymethylmethacrylate Blend Ultrafiltration Membranes, Sep. Sci. Technolo., 2010, 45:6, 740-750

9. Thakur, V. K.; Singha, A. S. Rapid Synthesis, Characterization, and Physicochemical Analysis of Biopolymer-Based Graft Copolymers, Int. J. Polym. Analy. Ch., 2011, 16:3, 153-164

10. Fuqin, H.; Desheng. X.; Qingwen, W.; Bo S.; Mo C. Thermal Properties of Carboxymethylcellulose and Methyl Methacrylate Graft Copolymers, J. Macro. Sci., Part B, 2013, 52:9, 1242-1249

11. Tarus B.; Fadel N.; Affaf Al-Oufy; Magdi El-Messiry, Effect of polymer concentration on the morphology and mechanical characteristics of electrospun cellulose acetate and poly (vinyl chloride) nanofiber mats, Alex. Eng. J., 2016, 55, 2975-2984

12. Ye, H.; Owh, C.; Jiang, S.; Ng, C.; Wirawan, D.; Loh, X. J. A thixotropic polyglycerol sebacate-based supramolecular hydrogel as an injectable drug delivery matrix. Polymers, 2016, 8, 130

13. Marek, K.; Jacques, L.; Anne M. D. Biodegradation of polyethylene films with prooxidant additives. Chemoshpere, 2006, 64, 1243 
14. Krishna B. D.; Selvakumar. M. Biodegradability of PMMA blends with some cellulose derivatives. J. Polym. Environ. 2006, 14, 385

15. Samion. E.; Dart. K. R.; Dawkins. C. J. Preparation, characterization and biodegradation studies on cellulose acetates with varying degrees of substitution. Polymer, 1997, 38, 3045

16. Muthukumar, N.; Maruthamuthu. S.; Palaniswamy, N. Role of cationic and nonionic surfactants on biocidal efficiency in diesel-water interface. Colloids Surf. B: Biointerfaces, 2007, 57, 152

17. Zhang, L.; Deng, X.; Zhao, S.; Huang, Z. Biodegradable polymer blends of poly (3-hydroxybutyrate) and hydroxyethyl cellulose acetate. Polymer, 1997, 38, 6001

18. Okada, M.; Yamada, M.; Yokoe, M.; Aoi, K. Biodegradable polymers based on renewable resources. V. Synthesis and biodegradation behavior of poly(ester amide)s composed of 1,4:3,6-dianhydro-Dglucitol, a-amino acid, and aliphatic dicarboxylic acid units. J. Appl. Polym. Sci., 2001, 81, 2721

19. Chandra, R.; Rustgi, R. Biodegradation of maleated linear low-density polyethylene and starch blends. Polym. Degrad. Stab., 1997, 56, 185

20. Peanasky, J.S.; Long, J. M.; Wool. R.F. Percolation effects in degradable polyethylene-starch blends. J. Polym. Sci. Polym. Phys. Ed., 1991, 18, 565

21. Seidenstucker, T.; Fritz, G. H. Innovative biodegradable materials based upon starch and thermoplastic poly (ester-urethane)(TPU). Polym. Degrad. Stab., 1998, 59, 279

22. Hadjiev. D.; Dimitrov, D.; Martinov, M.; Sire, O. Enhancement of the biofilm formation on polymeric supports by surface conditioning. Enzyme Microb. Technol., 2007, 40, 840

23. Goodlett. W.V.; Dougherty. T. J.; Patton. H.W. Characterization of cellulose acetates by nuclear magnetic resonance. J. Polym. Sci., Part A, 1971, 9, 155

24. Andrea, C.; Roberto, S.; Chiellini, E. Biodegradation of poly (vinyl alcohol) in selected mixed microbial culture and relevant culture filtrate. Polym. Degrad. Stab., 2002, 75, 447

\section{Figures}



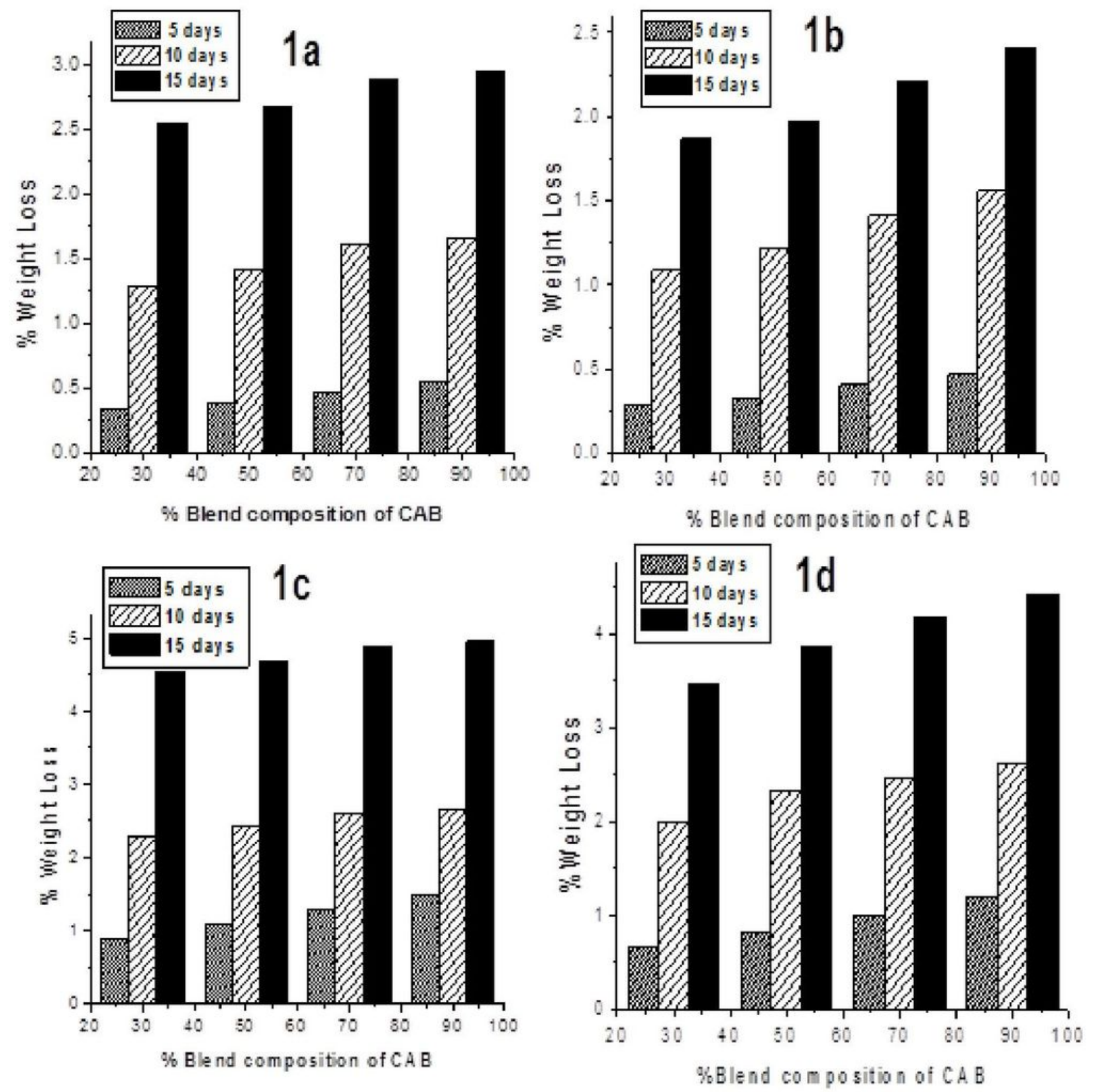

Figure 1

a, b Soil-burial degradation (1a) PMMA/CAB, (1b) PVC/CAB; 1b, c Enzyme degradation (1c) PMMA/CAB, (1d) PVC/CAB 

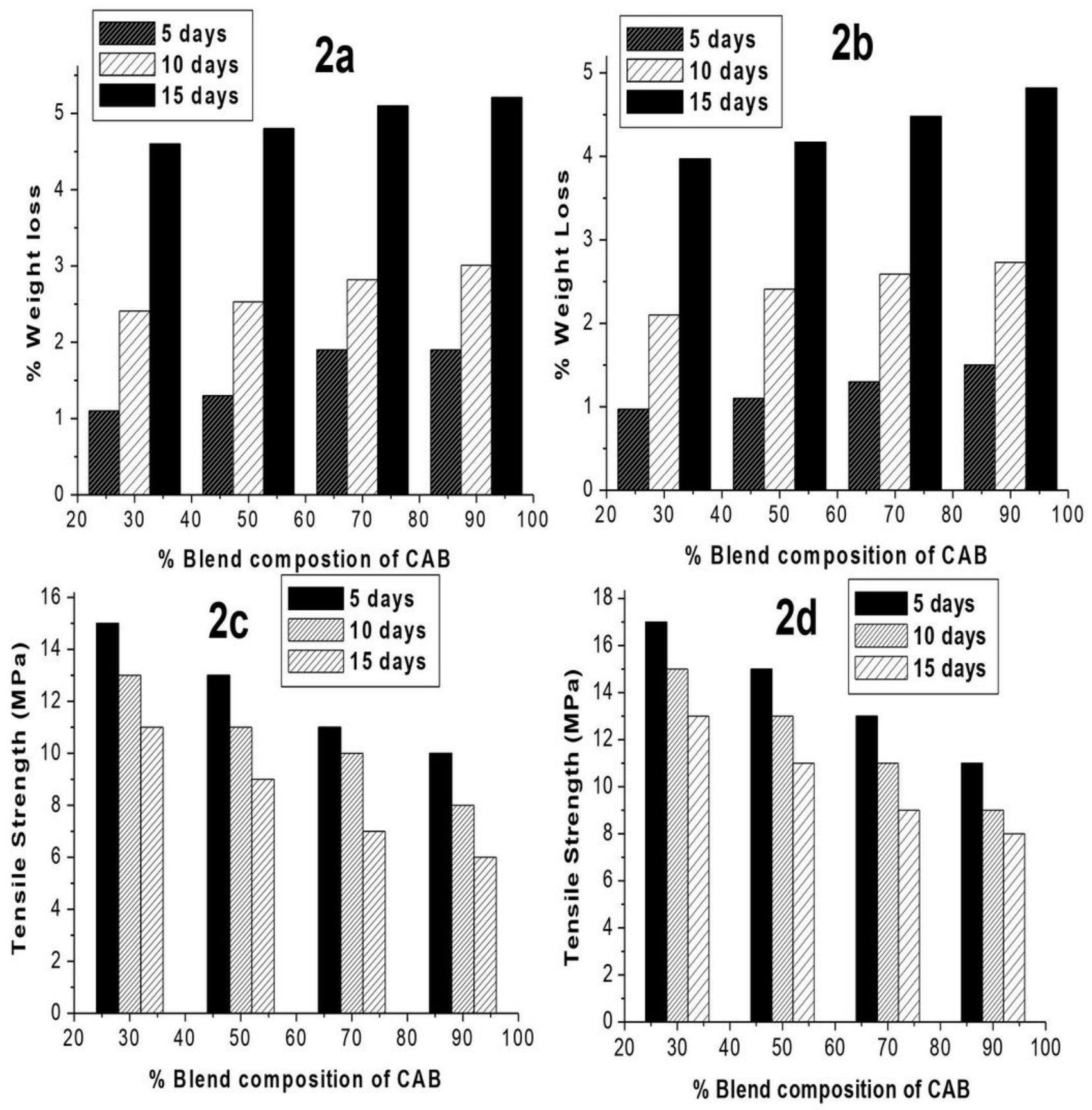

Figure 2

$a, b$ Activated sludge degradation (2a) PMMA/CAB, (2b) PVC/CAB; $1 b$, c tensile properties (2c) PMMA/CAB, (2d) PVC/CAB 


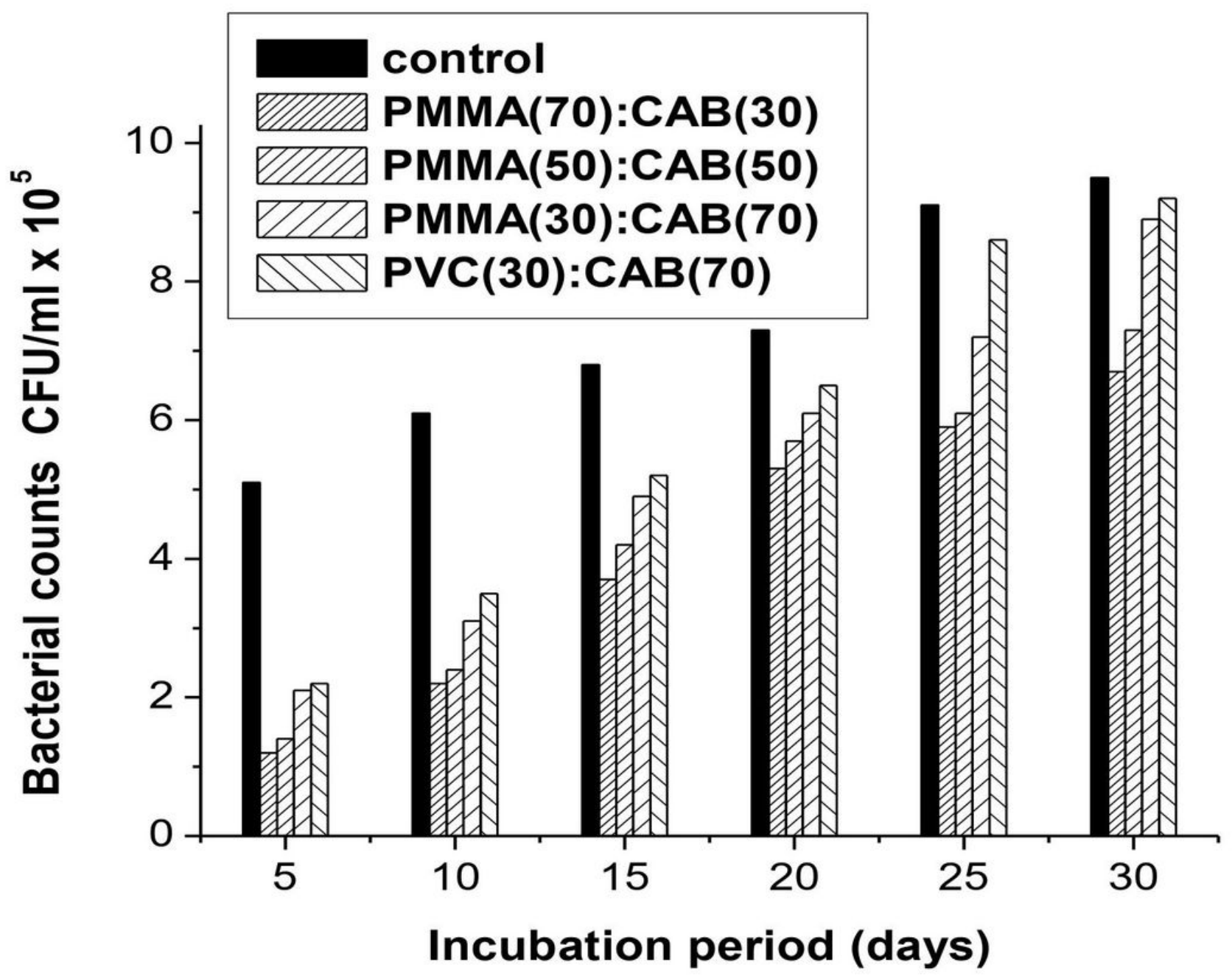

Figure 3

Bacterial growth chart, Control: without polymer blend film, PMMA/CAB(70:30), PMMA/CAB(50:50), PMMA/CAB(30:70), PVC/CAB(30:70) 

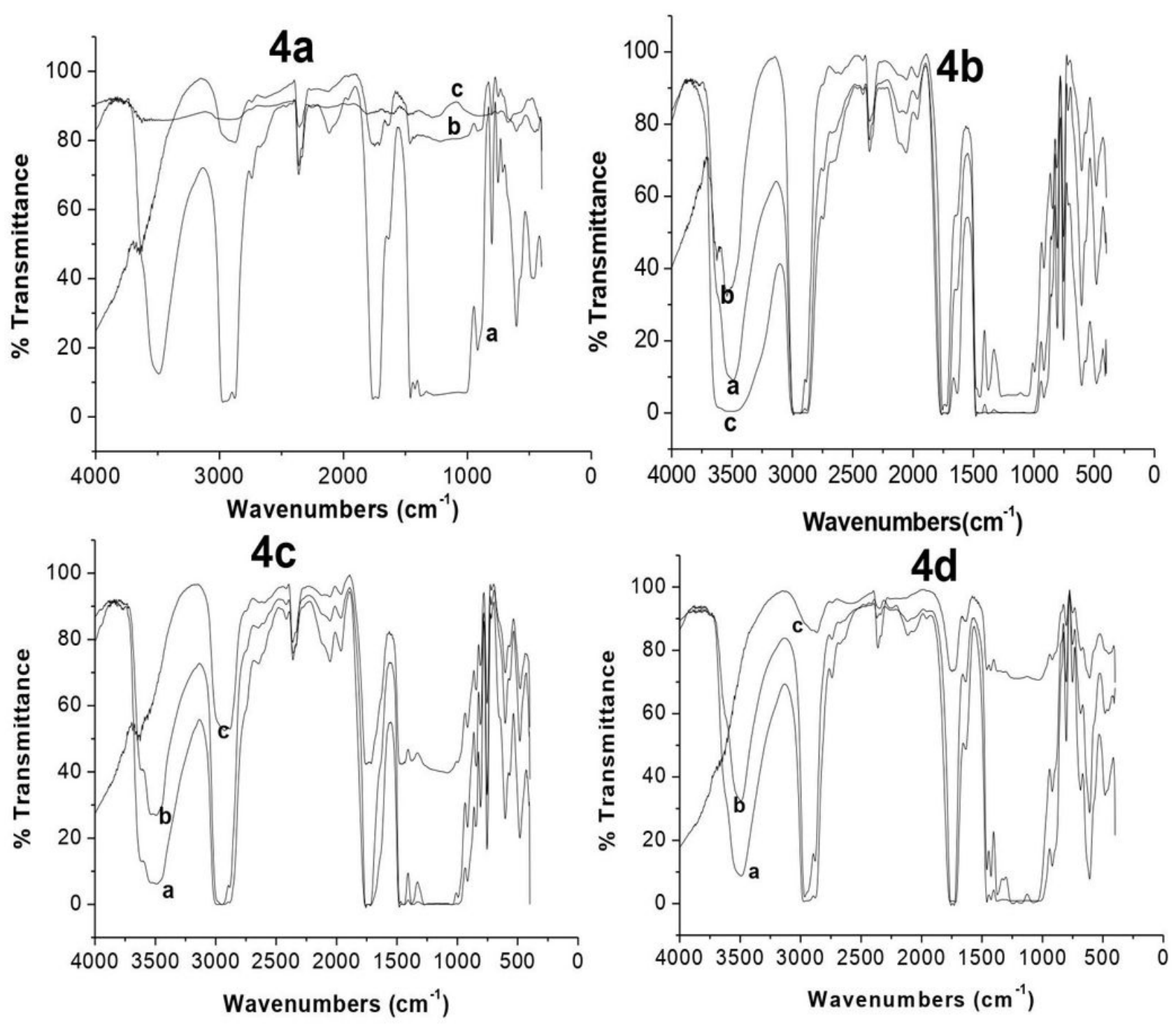

Figure 4

FTIR spectra of (4a) CAB (a) Before degradation (b) After 30 days of bacteria degradation (c) after 30 days of enzyme degradation; (4b) PMMA/CAB (30:70) (a) Before degradation (b) After 30 days of bacteria degradation (c) After 30 days of enzyme degradation; (4c) PMMA/CAB (50:50) (a) Before degradation (b) After 30 days of bacteria degradation (c) after 30 days of enzyme degradation; (4d) $\mathrm{PVC} / \mathrm{CAB}(30: 70)$ (a) Before degradation (b) After 30 days of bacteria degradation (c) After 30 days enzyme of degradation 
Fig. 5a

Before degradation

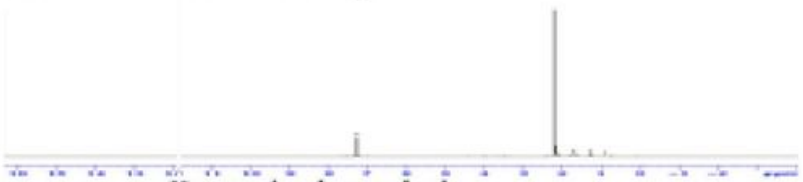

Bacteria degradation

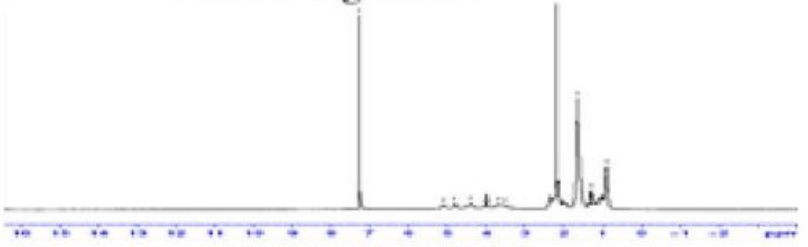

Enzyme degradation

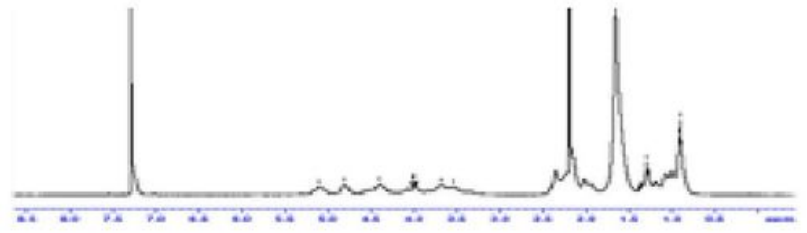

Fig. $5 c$

Before degradation
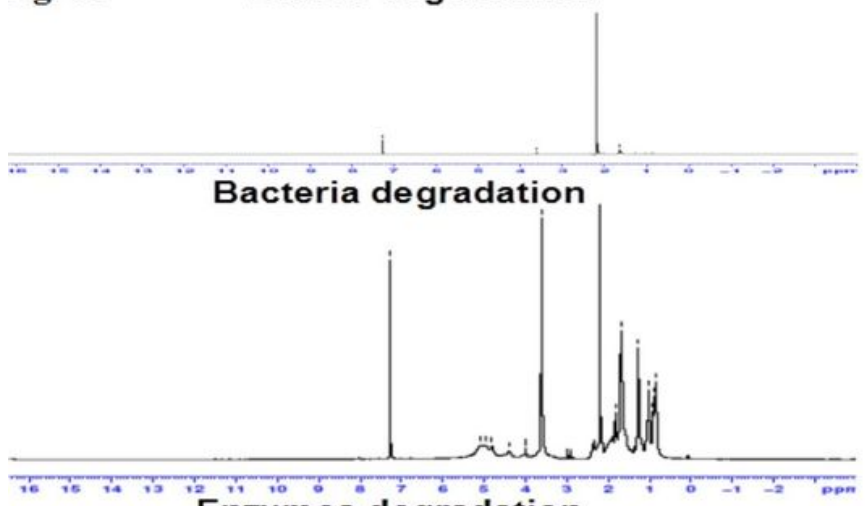

Enzymes degradation

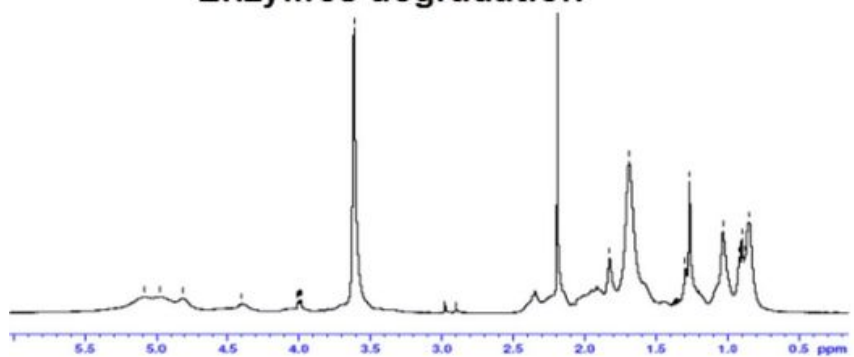

Fig. 5b

Before degradation

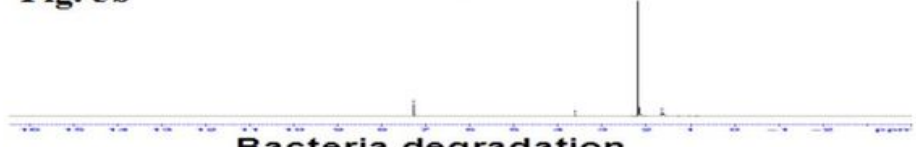

Bacteria degradation
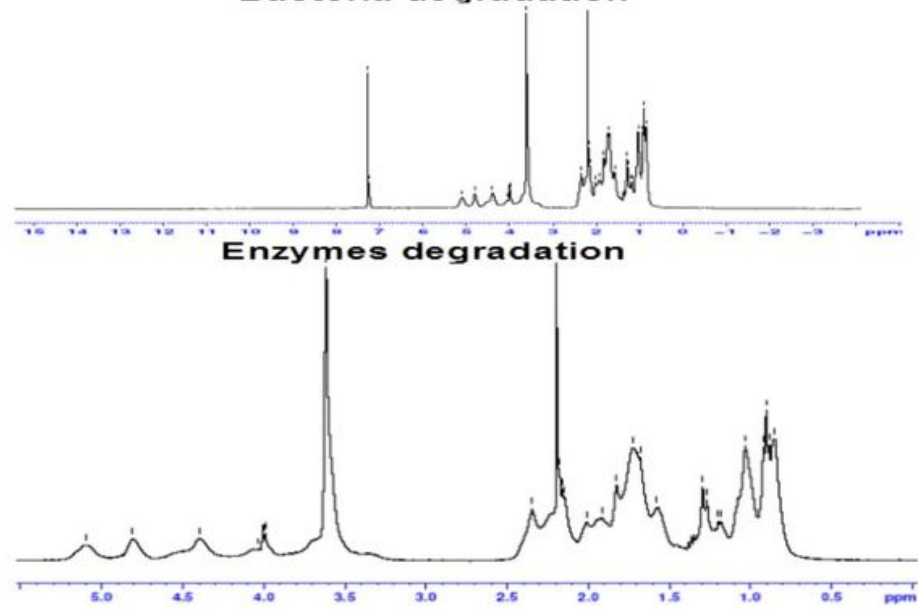

Fig. 5d
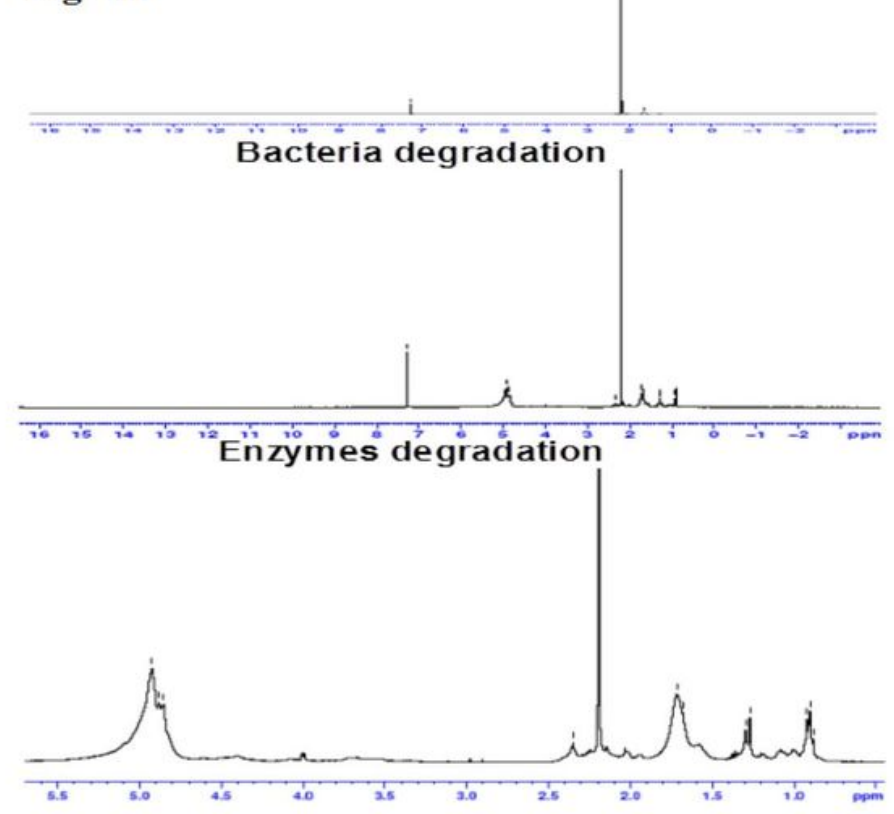

Figure 5

NMR spectra of (5a) CAB (a) Before degradation (b) After 30 days of bacteria degradation (c) after 30 days of enzyme degradation; (5b) PMMA/CAB (30:70) (a) Before degradation (b) After 30 days of bacteria degradation (c) After 30 days of enzyme degradation; (5c) PMMA/CAB (50:50) (a) Before degradation (b) After 30 days of bacteria degradation (c) after 30 days of enzyme degradation; ( $5 \mathrm{~d}$ ) PVC/CAB (30:70) (a) Before degradation (b) After 30 days of bacteria degradation (c) After 30 days enzyme of degradation 

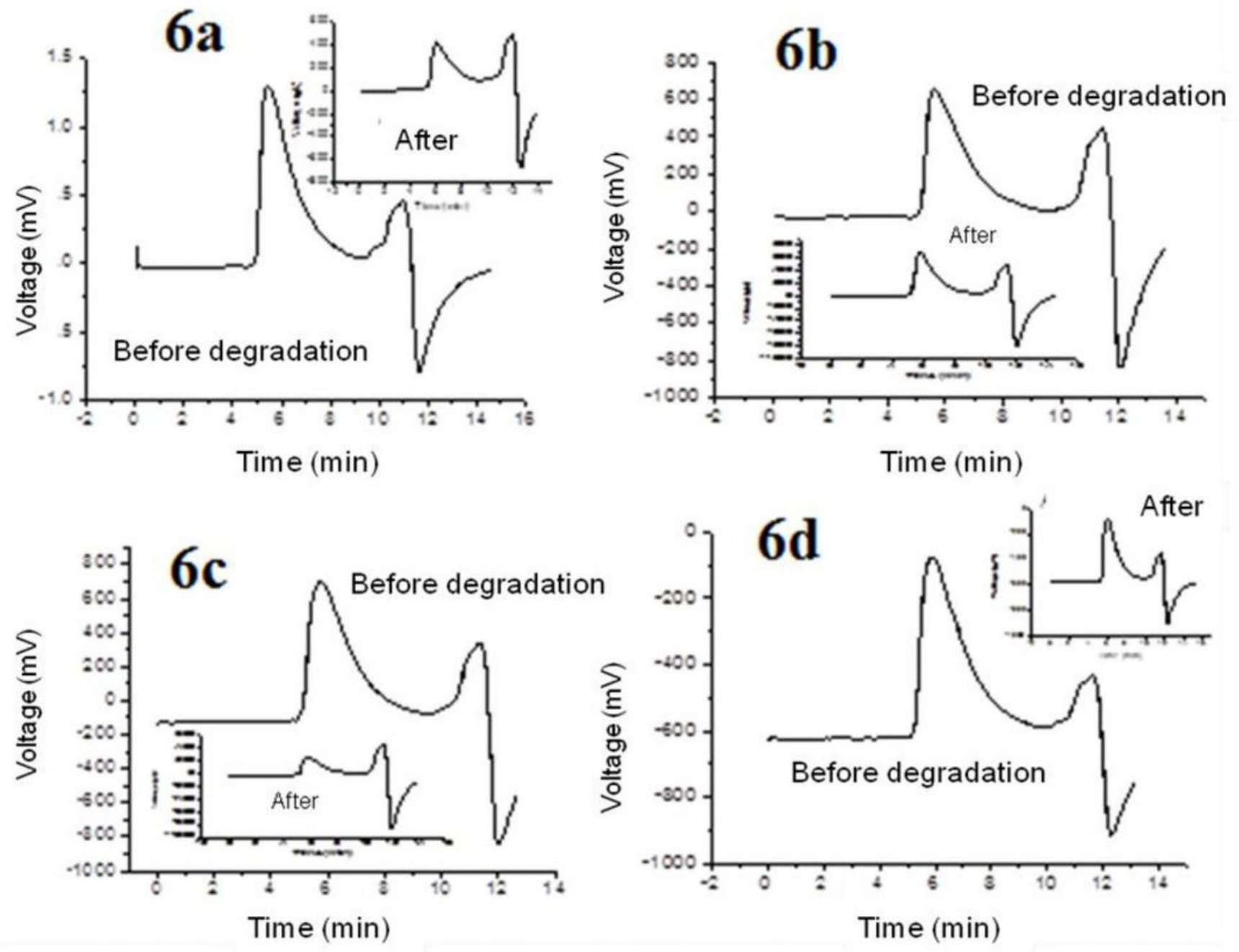

Figure 6

(6a) CAB (a) Before degradation (b) After 30 days of bacteria degradation; (6b) PMMA/CAB (30:70) (a) Before degradation (b) After 30 days of bacteria degradation; (6c) PMMA/CAB (50:50) (a) Before degradation (b) After 30 days of bacteria degradation; (6d) PVC/CAB (30:70) (a) Before degradation (b) After 30 days of bacteria degradation. 


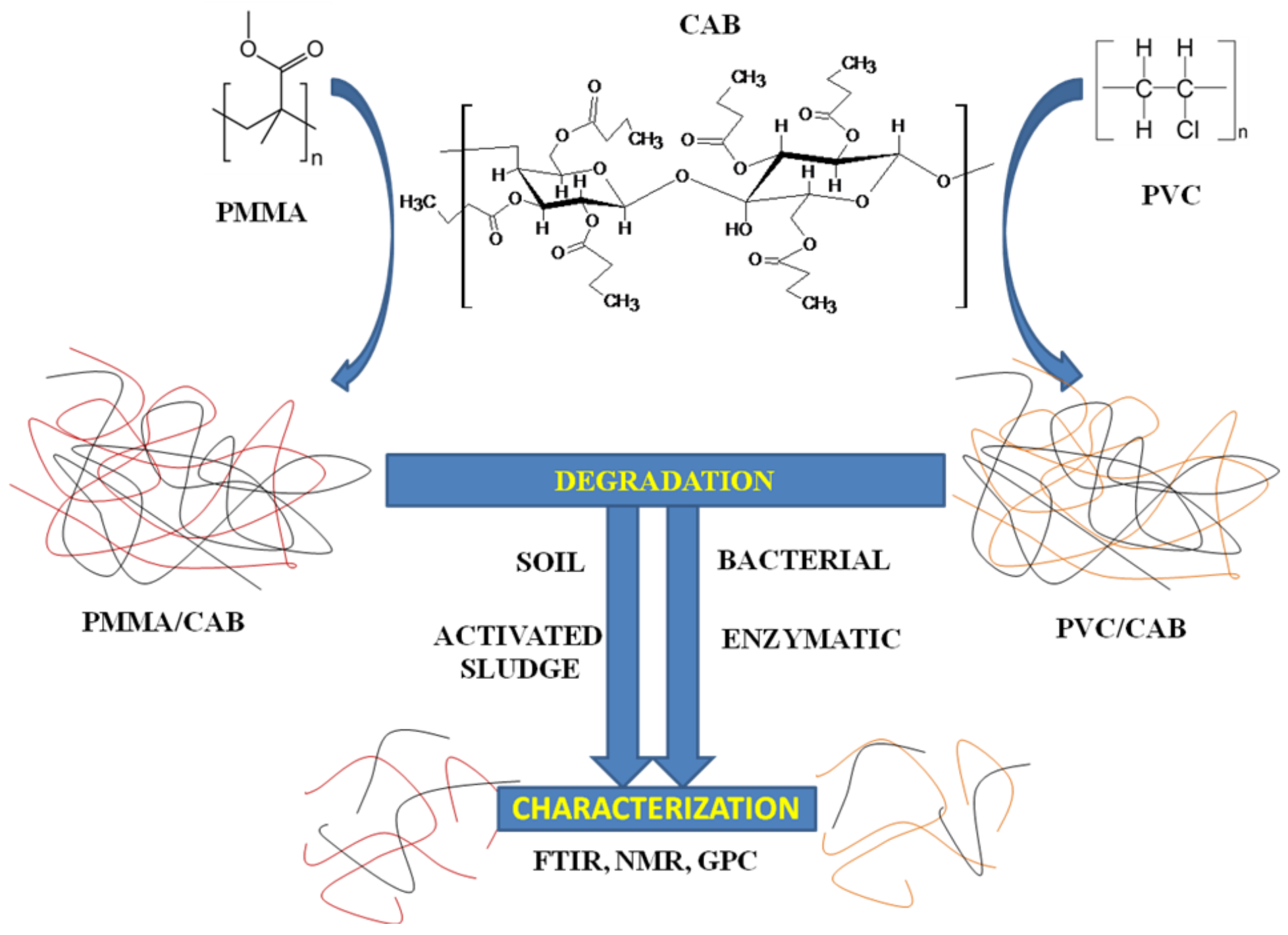

Figure 7

Scheme 1. Preparation and biodegradation investigation of polymer blends. 